\title{
Editorial
}

\section{Coverage of Acta Dermatovenerologica Alpina, Pannonica et Adriatica in Elsevier's CiteScore index: a new tool for measuring the citation impact of academic journals}

\author{
Mario Poljak ${ }^{1,2} \otimes$
}

\begin{abstract}
In December 2016, Elsevier launched a new tool that helps measure the citation impact of academic journals, called the CiteScore index. The CiteScore index values for 2015 confirmed the status of Acta Dermatovenerologica Alpina, Pannonica et Adriatica (Acta Dermatovenerol $A P A)$ as the leading journal in dermatology and sexually transmitted infections in the region. Sixty-five articles published in Acta Dermatovenerol APA from 2012 to 2014 received a total of 77 citations in 2015, resulting in a CiteScore index value of 1.18 for the journal. More than half of the articles published from 2012 to 2014 received at least one citation in 2015 . Acta Dermatovenerol APA performed well in all three categories listed because it is ranked 384 th out of 1,549 journals in the category General Medicine (75th percentile), 53rd out of 122 journals in the category Dermatology (56th percentile), and 142 nd out of 246 journals in the category Infectious Diseases (42nd percentile).
\end{abstract}

Received: 15 January 2017 | Returned for modification: 12 February 2017 | Accepted: 16 February 2017

After the recent acceptance of Acta Dermatovenerologica Alpina, Pannonica et Adriatica (Acta Dermatovenerol APA) for coverage in Thomson Reuters' new index in the Web of Science Core Collection called the Emerging Sources Citation Index (ESCI) (1), the editorial office has more good news for the journal's authors and readers.

In December 2016, the publishing giant Elsevier launched a new tool that helps measure the citation impact of academic journals, called the CiteScore index (https://journalmetrics.scopus. $\mathrm{com} /$ ). Although the CiteScore index ranks journals with a formula that largely mimics the influential Thomson Reuters' Journal Impact Factor (JIF), it covers twice as many journals: approximately 22,000 in comparison to JIF's 11,000. The journals covered in the CiteScore index calculation are those indexed in Elsevier's Scopus database, which-aside from Web of Science, which JIF is based on-is the world's only reasonably comprehensive and carefully curated citation database (2). To score any journal in any given year, both CiteScore and JIF count the citations received to articles that were published in previous years, and divide that by the total number of articles published (2). However, there is an important difference: JIF looks at research articles published in the previous 2 years, whereas CiteScore looks at those published in the previous 3 years. For example, the CiteScore index for 2015 is calculated as the ratio of the number of citations received in 2015 by all items published in a given journal in 2012, 2013, and 2014 and the sum of items published in the journal in 2012, 2013, and 2014. CiteScore values are freely available online (https://journalmetrics.scopus.com/), although full details of the documents in- cluded in the calculations are visible only to subscribers (2).

As Acta Dermatovenerol APA's readers are well aware, our editorial office is constantly monitoring the impact of the articles published in the journal, including citations in various databases. Each year Acta Dermatovenerol APA's predicted JIF was calculated in a way to match the official JIF published annually in Thomson Scientific Journal Citation Reports (3). Annual citation analyses have shown a substantial increase in the predicted JIFs since 2006, with values constantly above 0.5 since 2007. For the first time in the journal's history, a predicted JIF value above 1.0 was recorded in 2013 (3).

We are proud to announce that Acta Dermatovenerol APA's CiteScore index values for 2015 (the most recent data available) are even more encouraging. As summarized in Table 1, 65 articles published in Acta Dermatovenerol APA from 2012 to 2014 received a total of 77 citations in 2015, resulting in a CiteScore index value of 1.18 for the journal. More than half of the articles published from 2012 to 2014 received at least one citation in 2015 (Table 1). Interestingly, Acta Dermatovenerol APA was recognized by Elsevier as a very broad medical journal because it is listed in three different categories: General Medicine, Dermatology, and Infectious Diseases. In 2015, Acta Dermatovenerol APA performed well in all three categories because it is ranked 384th out of 1,549 journals in the category General Medicine (75th percentile), 53rd out of 122 journals in the category Dermatology (56th percentile), and 142nd out of 246 journals in the category Infectious Diseases (42nd percentile; Table 1).

Table 1 | Key Acta Dermatovenerol APA CiteScore index values for 2015.

\begin{tabular}{|c|c|c|c|c|c|c|}
\hline Category & CiteScore & $\begin{array}{l}\text { CiteScore } \\
\text { percentile }\end{array}$ & $\begin{array}{c}\text { CiteScore } \\
\text { rank }\end{array}$ & $\begin{array}{c}\text { Citations } \\
2015\end{array}$ & $\begin{array}{l}\text { Documents } \\
2012-2014\end{array}$ & $\begin{array}{c}\% \\
\text { cited }\end{array}$ \\
\hline General Medicine & 1.18 & 75th & $384 / 1,549$ & 77 & 65 & $54 \%$ \\
\hline Dermatology & 1.18 & 56th & $53 / 122$ & 77 & 65 & $54 \%$ \\
\hline Infectious Diseases & 1.18 & 42nd & $142 / 246$ & 77 & 65 & $54 \%$ \\
\hline
\end{tabular}


In conclusion, the first CiteScore index values released confirm that Acta Dermatovenerol APA is the leading journal in dermatology and sexually transmitted infections in the region. Following this important step in international recognition, we ask all of

\section{References}

1. Poljak M, Miljković J, Triglav T. Editorial: Acta Dermatovenerologica Alpina, Pannonica et Adriatica accepted for coverage in Thomson Reuters' Emerging Sources Citation Index (ESCl). Acta Dermatovenerol Alp Pannonica Adriat. 2016;25:39-40.

2. van Noorden R. Controversial impact factor gets a heavyweight rival. Nature. 2016;540:325-6. our readers once again to strongly consider submitting their best original manuscripts, case reports, and reviews to Acta Dermatovenerol $A P A$.

3. Oštrbenk A, Poljak M. Citation analysis of Acta Dermatovenerologica Alpina, Pannonica et Adriatica: 1992-2013. Acta Dermatovenerol Alp Pannonica Adriat. 2015;24:1-3. 